\title{
Tiếp tục đổi mới, hoàn thiện chế độ sở hữu trong nền kinh tế thị trường định hướng XHCN ở Việt Nam
}

\author{
Võ Đại Lược \\ Tạp chí Mặt trận \\ August 24, 2021
}

http://tapchimattran.vn/kinh-te/tiep-tuc-doi-moi-hoanthien-che-do-so-huu-trong-nen-kinh-te-thi-truong-dinhhuong-xhcn-o-viet-nam-40550.html 


\section{Tiếp tục đổi mới, hoàn thiện chế độ sở hũu trong nền kinh tế thị trường định hướng XHCN ở Việt Nam}

Nền kinh tế thị trường thực sự hiện đang tồn tại ở tất cả các nước phát triển với các mô hình khác nhau. Nhưng tất cả đều có những đặc điểm chung, đó là: (1) Cơ sở vật chất và công nghệ đều dựa trên sự phát triển của đại công nghiệp và đang có xu hướng chuyển sang nền kinh tế tri thức; (2) Các nền kinh tế thị trường này đều dựa trên nền tảng sở hữu tư nhân, sở hữu nhà nước, chiếm tỷ trọng không lớn và chỉ có vai trò hỗ trợ sở hữu tư nhân phát triển; (3) Giá cả của tất cả các loại hàng hóa và dịch vụ như: giá cả, lãi suât, tỷ giá, tiền lương... đều do thị trường xác định, có sự điều tiết hợp lý của nhà nước khi cần thiết; (4) Các nguồn lực phát triển: tiền tệ, vốn, công nghệ, lao động... do thị trường phân bổ; (5) Các nền kinh tế thị trường này đều mở cửa, hội nhập quốc tế; (6) Nhà nước đều can thiệp để hạn chế bớt mặt trái của thị trường, như: giảm bớt tình trạng nghèo đói, ô nhiễm môi trường, tác động tiêu cực của khủng hoảng, định hướng hỗ trợ phát triển khoa học công nghệ và hội nhập quốc tế...

\section{Nhũng quan điểm về chế độ sở hữu}

\section{Chế độ sở hũu phải phù họp vơi trình độ phát triển của lực lưọng sản xuất}

Chế độ sở hữu nô lệ tồn tại trên cơ sở kinh tế hái lượm và săn bắn, nhưng khi nền kinh tế trồng trọt và chăn nuôi xuất hiện, thì chế độ sở hữu nô lệ cũng không còn cơ sở để tồn tại. Nhưng khi các công trường thủ công xuất hiện nền văn minh công nghiệp phát triển, thì chế độ sở hữu ruộng đất phong kiến cũng không thể tồn tại, chế độ sở hữu tư nhân tư bản chủ nghĩa đã xuất hiện và thay thế nó. Ngay chính chế độ sở hữu tư nhân tư bản chủ nghĩa cũng luôn tự điều chỉnh và phát triển phù hợp với trình độ phát triển của đại công nghiệp. Nước Anh với nền văn minh công nghiệp đã thống trị thế giới. Nhưng nền văn minh công nghiệp đã nhường chỗ cho nền văn minh tài chính với chế độ sở hữu tư bản (chứ không phải là sở hữu nhà máy), nước Mỹ đã thống trị thế giới bằng nền văn minh tài chính. Người ta đang nói tới thời kỳ tàn lụi của văn minh tài chính, một nền kinh tế tri thức đã xuất hiện, chế độ sở hữu trí tuệ sẽ thống trị và các nhân tài sẽ có vai trò chi phối thế giới này. C.Mác đã khái quát mối quan hệ phụ thuộc này thành quy luật thích ứng giữa quan hệ sản xuất với trình độ phát triển của lực lượng sản xuất và quy luật này chi phối sự phát triển của các chế độ sở hữu và do đó cả các chế độ xã hội với câu nói nổi tiếng là "Cái cối xay tay đem lại xã hội có vua chúa, cái cối xay chạy bằng hơi nước đem lại xã hội có chủ nghĩa tư bản công nghiệp”1.

Quá trình đổi mới chế độ sở hữu ở nước ta cũng đang và sẽ bị chi phối bởi quy luật này. Chế độ sở hữu trước đổi mới năm 1986 là chế độ không phù hợp với trình độ phát triển của lực lượng sản xuất nước ta lúc đó rõ rệt nhất.

\section{Các hình thức sở hữu ngày càng đa dạng và luôn bị chi phối bởi hình thức sở hữu tiên tiến nhất}

Sự phát triển của các hình thức sở hữu ngày càng đa dạng, từ chế độ sở hữu nô lệ, chế độ sở hữu ruộng đất đến chế độ sở hữu tư bản chủ nghĩa hiện đại. Chế độ sở hữu nô lệ là chế độ tư hữu thuần nhất của các chủ nô lệ. Chế độ sở hữu ruộng đất phong kiến có hình thức sở hữu: tư và công, trong đó hình thức tư hữu ruộng đất là hình thức tiên tiến nhất có vai trò chi phối dưới chế độ phong kiến. Chế độ sở 
hữu tư bản chủ nghĩa hiện đại đã ngày càng đa dạng gồm: sở hữu tư nhân, sở hữu nhà nước, sở hữu cổ phần và hình thức sở hữu cổ phần là hình thức sở hữu xã hội tiên tiến nhất, phổ biến nhất và có vai trò chi phối nhất trong xã hội tư bản chủ nghĩa hiện đại. Hình thức của cải của xã hội phổ biến không phải là hàng đống hàng hóa, hay là hàng triệu nhà máy, mà là chứng khoán, các giấy tờ có giá được lưu hành trên thị trường tài chính. Những của cải vật chất của các chủ sở hữu có thể vẫn tồn tại bất động, nhưng giá trị thực của nó đã lưu thông, vận động khôn cùng trên các thị trường tài chính, các chủ sở hữu tư nhân, hay nhà nước cũng phải nắm giữ các công cụ tài chính quan trọng này. Các chính phủ hiện đại đang điều chỉnh nền kinh tế bằng các công cụ tài chính là chính chứ không phải bằng các mệnh lệnh. Lãi suất, thuế, tỷ giá, công trái... là các công cụ chính của các chính phủ này, các công ty muốn huy động vốn chủ yếu phải bằng phát hành trái phiếu công ty trên thị trường chứng khoán là chính, chứ không phải bằng vay ngân hàng.

\section{Các quan hệ sở hũu phải được thể chế hóa theo hướng hiện đại mói có giá trị thực tế}

Các quan hệ sở hữu phải được bảo vệ bằng hệ thống thể chế chính thức của nhà nước mới có giá trị thực tế. Quyền sở hữu tư nhân là quyền sở hữu cơ bản của mọi nền kinh tế thị trường phải được bảo vệ trước hết, phải được thể chế hóa trước hết. Các bộ luật dân sự, luật kinh tế phải thể hiện yêu cầu này. Tất cả các quan hệ sở hữu đa dạng trên mọi lĩnh vực từ tư liệu sản xuất đến tư liệu tiêu dùng, từ lĩnh vực bất động sản đến tài chính, từ sở hữu các sản phẩm vật chất đến sở hữu trí tuệ... đều phải được thể chế hóa. Hình thức của cải của xã hội đã phát triển và tiến hóa, chế độ sở hữu cũng vậy, đã tiến từ sở hữu đất đai, sở hữu các tư liệu sản xuất, sở hữu các loại cổ phiếu, trái phiếu chứng khoán đến sở hữu trí tuệ. Các thể chế cũng luôn được đổi mới để phù hợp với các hình thức sở hữu trên.

Các nền kinh tế thị trường phát triển đã trải qua hơn 4 thể kỷ điều chỉnh, thích ứng của các loại thể chế liên quan đến chế độ sở hữu, do vậy những thể chế này đã càng hoàn thiện và ngày càng được hiện đại hóa. Các nền kinh tế thị trường kém phát triển có được lợi thế đi sau - có thể rút ngắn con đường thể chế hóa các quan hệ sở hữu theo hướng hiện đạiz.

Quan hệ sở hữu liên quan đến toàn bộ quá trình sản xuất, lưu thông, phân phối và tiêu dùng, do vậy việc thể chế hóa quan hệ sở hữu phải là sự thể chế hóa toàn bộ quá trình đó, không thể thể chế hóa từng khâu, từng bộ phận.

Việc thể chế hóa các quan hệ sở hữu không chỉ dừng ở việc lập pháp, mà phải tính đến cả việc xây dựng các cơ quan thực thi, kiểm tra, giám sát...

\section{Cải cách chế độ sở hữu ở Việt Nam phải theo hướng hiện đại}

Chế độ sở hữu ở Việt Nam hiện nay đã có những đổi mới rất cơ bản, nhưng vẫn còn những khác biệt rất lớn so với chế độ sở hữu ở các nền kinh tế thị trường hiện đại: (1) Trong cơ cấu của chế độ sở hữu Việt Nam, tỷ trọng của sở hữu nhà nước lớn, chiếm tới $28 \%$ GDP, nếu kể cả các ngân hàng thương mại nhà nước thì tỷ trọng này tới $34 \%$ GDP, trong khi ở các nền kinh tế thị trường phát triển, tỷ trọng này chỉ dưới 10\%; (2) Kinh tế nhà nước giữ vai trò chủ đạo, trong khi ở các nền kinh tế thị trường phát triển, kinh tế nhà nước không có vai trò này; (3) Sở hữu tư nhân là nền tảng của các nền kinh tế thị trường hiện đại, thì ở Việt Nam sở hữu tư nhân chưa có vai trò đó; (4) Kinh tế thị trường ở Việt Nam theo định hướng xã hội chủ nghĩa, còn các nền kinh tế thị trường phát triển không có định hướng chính trị.

Do vậy, công cuộc đổi mới và hoàn thiện chế độ sở hữu ở Việt Nam phải hướng tới 
việc khắc phục những hạn chế trên và đạt tới sức cạnh tranh ngang hàng với các nền kinh tế thị trường hiện đại khác. Quá trình cải cách này cần có những bước đi phù hợp: Trước hết, phải phát triển mạnh mẽ khu vực kinh tế tư nhân để khu vực này dần dần có thể thay thế các doanh nghiệp nhà nước ở những lĩnh vực nhà nước không cần nắm giữ; Thực hiện cổ phần hóa doanh nghiệp nhà nước3, nhà nước rút vốn ra khỏi những lĩnh vực không cần nắm giảm tỷ trọng của doanh nghiệp nhà nước xuống mức thích hợp, tạo điều kiện cho khu vực tư nhân phát triển; Thực hiện việc phân bổ các nguồn lực theo cơ chế thị trường cạnh tranh, theo các tín hiệu giá cả thị trường như giá cả hàng hóa dịch vụ, lãi suất, tỷ giá, tiền lương; Xây dựng các thị trường yếu tố, đặc biệt là thị trường bất động sản và thị trường tài chính là hai thị trường có ý nghĩa chi phối, khuyến khích cạnh trạnh, kiểm soát độc quyền.

\section{Nhà nước luôn có vai trò quan trọng trong tiến trình đổi mới và hoàn thiện chế độ sở hữu}

Ở những nền kinh tế đã phát triển, thị trường đã hoàn thiện, nhà nước chỉ giữ vai trò hỗ trợ thị trường, khắc phục các yếu kém của thị trường và để làm điều này khu vực sở hữu nhà nước nói chung là nhỏ, nhà nước không cần có khu vực sở hữu lớn cũng có thể làm được vai trò đó. Song, dù là nhỏ cũng phải có và dường như sự tồn tại của sở hữu nhà nước có tính tất yếu khách quan.

Những nền kinh tế kém và đang phát triển khu vực sở hữu nhà nước thường có tỷ trọng lớn, và chiếm giữ những ngành và lĩnh vực quan trọng. Nhà nước thường sử dụng khu vực này để định hướng và ổn định nền kinh tế. Chẳng hạn nhà nước có thể xây dựng một số nhà máy, sau đó bán lại cho tư nhân, rút vốn ra, tiếp tục xây dựng các nhà máy khác, lại bán cho tư nhân.

Vai trò quan trọng nhất của nhà nước là khuyến khích khu vực tư nhân phát triển, bảo vệ quyền sở hữu tư nhân, định vị khu vực sở hữu nhà nước một cách hợp lý và thường là ở những lĩnh vực tư nhân không làm được.

\section{Những kiến nghị về giải pháp đổi mới hoàn thiện chế độ sở hữu}

\section{Trước hết phải đổi mới quan điểm về chế độ sở hữu}

Quan điểm phát triển chế độ sở hữu ở nước ta phải ngày càng tiếp cận với các quan điểm phát triển chế độ sở hữu của các nền kinh tế thị trường hiện đại, đó là:

+ Khu vực sở hữu nhà nước là cần thiết và tồn tại như một tất yếu khách quan và giữ vai trò hỗ trợ cho khu vực kinh tế tư nhân, góp phần định hướng phát triển chủ yếu ở một số ngành công nghiệp quốc phòng, công nghệ tiên tiến, dịch vụ công...

+ Khu vực sở hữu tư nhân là nền tảng của nền kinh tế, phải được khuyến khích phát triển và bảo vệ các quyền cần thiết.4

+ Sở hữu cổ phần là hình thức sở hữu phổ biến và tiên tiến cần tạo dựng các điều kiện cần thiết cho phát triển, đặc biệt là phát triển thị trường tài chính đa dạng. Trước hết phải xây dựng các thể chế hiện đại cho các thị trường tài chính, đặc biệt là thị trường chứng khoán, tạo điều kiện cho tất cả các doanh nghiệp cả của nhà nước và tư nhân có thể phát hành cổ phiếu, trái phiếu trên thị trường chứng khoán. Đồng thời, phải tuyển chọn những nhà quản lý tài năng vào các vị trí quản trị các thị trường này, kể cả các nhà quản lý nước ngoài.

\section{Sở hữu nhà nước và vai trò chủ đạo của kinh tế nhà nước phải được đổi} mới 
+ Giảm tỷ trọng của khu vực doanh nghiệp nhà nước xuống mức phù hợp với thị trường thế giới, nhà nước cần xây dựng một chương trình rút vốn khỏi tât cả các doanh nghiệp nhà nước mà nhà nước không cần nắm giữ, trước hết là những doanh nghiệp nhà nước hiện kinh doanh có lãi như rượu, bia, nước giải khát... Thực tế thế giới cho thấy, nếu nhà nước bán các doanh nghiệp nhà nước này trên thị trường chứng khoán, nhường cho tư nhân, thì khoản thuế mà nhà nước thu được sẽ lớn hơn lợi tức mà nhà nước thu khi làm chủ sở hữu. Giải pháp này không chỉ giúp nhà nước có được một khoản vốn lớn từ các doanh nghiệp nhà nước này, mà còn là cú hích thúc đẩy thị trường chứng khoán Việt Nam phát triển.

+ Xây dựng và thực hiện quyết liệt một chương trình cổ phần hóa bắt buộc đối với tất cả các doanh nghiệp nhà nước mà Nhà nước không cần nắm giữ từ $51 \%$ đến 100\%. Những doanh nghiệp nhà nước này hiện còn nhiều trong các lĩnh vực như thương mại, công nghiệp sản xuất hàng tiêu dùng, kể cả các lĩnh vực sản xuất tư liệu sản xuất thông thường.

+ Áp dụng cơ chế cổ phần hóa hiện đại theo hướng công khai minh bạch, đấu thầu các cổ phiếu này trên thị trường chứng khoán, cấm việc bán cổ phiếu chỉ trong nội bộ doanh nghiệp, bán cho những người quản lý doanh nghiệp, vì đây là hành vi dễ bị lợi dụng làm thất thoát tài sản nhà nước.

+ Chương trình này phải tối thiểu hóa các doanh nghiệp nhà nước, mà nhà nước nắm giữ 51-100\% cổ phần. Thực hiện cơ chế quản trị doanh nghiệp hiện đại theo các chuẩn mực của các nước phát triển. Thực hiện chế độ thi tuyển cạnh tranh các chức vụ quản lý quan trọng trong các doanh nghiệp nhà nước.

\section{Đổi mói chế độ sở hữu đất đai theo hướng đảm bảo sử dụng đất có hiệu quả}

Về quản lý nhà nước cũng cần có những đổi mới: Nhà nước phải xây dựng quy hoạch, kế hoạch sử dụng đất đai, có chế tài giám sát việc thực hiện; Thực hiện đấu giá quyền sử dụng đất theo các nguyên tắc của thị trường, công khai, minh bạch, bãi bỏ chế độ "xin - cho"; Nhà nước phải quy định việc phân phối lại lợi ích phát sinh từ quá trình chuyển đổi công năng, mục đích sử dụng đât, từ hoạt động đầu tư cơ sở hạ tầng làm tăng giá trị đất... Hoàn thiện hệ thống đăng ký đất đai, bất động sản, cơ chế cấp giấy chứng nhận quyền sử dụng đất, giấy chứng nhận quyền sở hữu nhà ở và các tài sản gắn liền với đất, đây là cơ sở pháp lý cơ bản cho thị trường bất động sản hoạt động hiệu quả. Xây dựng và hoàn thiện hệ thống dữ liệu về đất đai và bất động sản, công bố công khai các thông tin cần thiết về quy hoạch, kế hoạch sử dụng đất, các biến động về giá cả, các kế hoạch xây dựng kết cấu hạ tầng gắn với đất... Xây dựng và hoàn thiện các cơ chế hoạt động của thị trường bất động sản theo hướng hiện đại, đảm bảo cho thị trường bất động sản phát triển bền vững, chống động cơ thổi giá bất động sản tăng cao phi lý. Hoàn thiện cơ chế định giá đất theo các nguyên tắc của thị trường.

\section{Đổi mới chế độ sở hũu trí tuệ theo hướng khuyến khích sáng tạo hũu hiệu, bảo vệ quyền sở hưu trên các lĩnh vụ̣c}

Thứ nhất, phải thúc đẩy, khuyến khích hoạt động sáng tạo ở Việt Nam trên tất cả các lĩnh vực để có thể tạo ra một dung lượng tri thức mới, các bằng phát minh sáng chế, các thương hiệu... Đây chính là tài sản quốc gia đáng giá nhất cần phải được bảo vệ. Nếu Việt Nam không có những tài sản này, thì Việt Nam chỉ có thể bảo vệ quyền sở hữu trí tuệ của người nước ngoài.

Thứ hai, phải hoàn thiện hệ thống thể chế gồm cả các luật lệ liên quan đến sở hữu trí tuệ, không chỉ những luật lệ bảo vệ quyền sở hữu trí tuệ, mà cả những luật lệ phát huy trí sáng tạo của người Việt Nam theo hướng hiện đại, nhất là các chế tài 
ngăn chặn các hành vi vi phạm, hoàn thiện hệ thống tổ chức liên quan đến việc bảo vệ quyền sở hữu trí tuệ, kể cả hệ thống tổ chức nghiên cứu sáng tạo.

Thứ ba, tăng cường các hoạt động dịch vụ thông tin truyền thông phổ biến các tri thức liên quan đến quyền sở hữu trí tuệ, cần đưa vấn đề quyền sở hữu trí tuệ vào nội dung giảng dạy ở các trường đại học.

Thứ tư, mở rộng sự hợp tác với các tổ chức nước ngoài để học hỏi kinh nghiệm, để đào tạo cán bộ, để hoàn thiện hệ thống pháp lý của Việt Nam theo hướng tiên tiến và hiện đại.

Thứ năm, thúc đẩy việc nhập khẩu các bằng phát minh sáng chế, cải tiến ứng dụng và thương mại hóa. Đây là một hoạt động quan trọng vì các bằng phát minh, sáng chế của Việt Nam còn hạn chế. Đây cũng là cách làm phổ biến của các nước đi sau.

Thứ sáu, đổi mới chính sách bồi dưỡng, trọng dụng nhân tài, lực lượng sáng tạo quan trọng của đất nước, theo hướng các bằng phát minh sáng chế phải được thương mại hóa, những nhà sáng chế phải được hưởng thù lao xứng đáng, sáng chế của họ phải được bảo vệ, họ phải được tôn vinh.

\section{Thuế tài sản cá nhân}

+ Quá trình đổi mới ở Việt Nam đã tạo điều kiện cho sự xuất hiện và phát triển của một tầng lớp giàu có. Số lượng triệu phú USD của Việt Nam đã tăng rất nhanh với tốc độ hàng đâu Đông Nam Á. Do vậy, số lượng tài sản của họ cũng tăng nhanh, những tài sản thừa kế cũng tăng nhanh. Song, số thuế thu được từ tài sản cá nhân, đặc biệt là thuế thừa kế lại rất nhỏ, mỗi năm chỉ mấy chục tỷ đồng. Hơn nữa số lượng tài sản của họ hiện là bao nhiêu cũng không có cơ quan nào kiểm soát, thống kê được, vì khồng có thông tin công khai minh bạch. Những tài sản này rất đa dạng, có thể là bất động sản, là chứng khoán, là cổ phiếu...

+ Phải kiểm kê tài sản của mọi người có tài sản từ 100 tỷ đồng trở lên một cách công khai minh bạch và phải có chế độ quy định cụ thể về việc đăng ký quyền thừa kế.

+ Có thể quy định mức thuế lũy tiến đối với tài sản thừa kế, khối lượng tài sản càng lớn mức chịu thuế càng cao.

+ Có chế độ khuyến khích những người giàu có lập các quỹ phúc lợi xã hội, thay vì để lại cho con cái. Quỹ phúc lợi xã hội này có thể được thành lập từ tiền của những người giàu có và được miễn mọi loại thuế.

\section{Sở hưu nước ngoài}

Trong các nền kinh tế thị trường hiện đại, người nước ngoài có quyền mua, bán và sở hữu mọi thứ từ bất động sản đến các cảng biển, sân bay, trừ những công trình liên quan đến an ninh quốc phòng. Đã có một giai đoạn người Nhật giàu có đã đua nhau mua các tài sản ở Mỹ từ các thương hiệu, công nghệ đến bất động sản. Hiện người giàu Trung Quốc cũng đang đua nhau mua tài sản ở Mỹ. Ngay cả Trung Quốc cũng đã cho phép người nước ngoài mua nhà cửa của Trung Quốc.

Ở Việt Nam từ khi có Luật Đầu tư nước ngoài năm 1988, người nước ngoài được đầu tư trực tiếp vào Việt Nam, được quyền thuê đất có thời hạn, được quyền đầu tư xây dựng các nhà máy công xưởng tại Việt Nam, được quyền kinh doanh trên nhiều lĩnh vực.

Các định hướng chính sách về sở hưu và các giải pháp nâng cao nhận thức xã hội 


\section{Các định hướng chính sách}

Thứ nhất, Nhà nước phải rút vốn ra khỏi các lĩnh vực kinh doanh kiếm lợi, kể cả các lĩnh vực kinh doanh kiếm lợi nhất, nhượng lại cho tư nhân kinh doanh trong các lĩnh vực này. Nhà nước không thu lợi nhuận nữa, nhưng Nhà nước sẽ thu thuế.

Thứ hai, khuyến khích phát triển mạnh mẽ doanh nghiệp tư nhân, giúp họ trở thành động lực chủ yếu của nền kinh tế thị trường Việt Nam. Tạo lập một môi trường kinh doanh cạnh tranh tự do, bình đẳng, không phân biệt đối xử. Để làm được việc này, mọi loại giá cả: giá cả hàng hóa, dịch vụ, lãi suất, tỷ giá, tiền lương... phải được tự do hóa, phải do thị trường định, Nhà nước chỉ tham gia điều tiết khi cần thiết. Sửa đổi các luật liên quan đến kinh doanh của doanh nghiệp tư nhân (luật dân sự, luật doanh nghiệp, luật đầu tư, luật phá sản, các luật thuế...) theo hướng bảo vệ quyền sở hữu tư nhân, đảm bảo quyền kinh doanh của doanh nghiệp tư nhân.

Thứ ba, thực thi chính sách Nhà nước, chuyển quyền phân bổ các nguồn lực cho thị trường. Thực hiện chính sách cổ phần hóa không chỉ đối với doanh nghiệp nhà nước, mà cả doanh nghiệp tư nhân, để có thể thúc đẩy xu hướng sở hữu cổ phần sẽ là hình thức phổ biến của nền kinh tế. Khuyến khích tất cả các doanh nghiệp cổ phần hóa sẽ bán cổ phiếu trên sàn chứng khoán. Hoàn thiện thị trường chứng khoán theo hướng hiện đại, theo chuẩn của các thị trường chứng khoán hiện đại nhất. Chuyển hướng huy động vốn của các doanh nghiệp không chỉ từ các ngân hàng, mà chủ yếu từ thị trường chứng khoán.

Thứ tư, đa dạng hóa chế độ sở hữu đất đai. Tiến hành quy hoạch đất đai dài hạn với tầm nhìn 100 năm. Đất đai dành cho xây dựng các cơ sở hạ tầng, các khu đô thị, các trường học, bệnh viện, các công sở... phải được xác định là thuộc sở hữu nhà nước. Đối với các loại đất còn lại: đất thố cư thuộc sở hữu cá nhân, đất cho doanh nghiệp - thuộc sở hữu tư nhân, đất nông nghiệp thuộc sở hữu tập thể... cần sớm được nghiên cứu xác định.

\section{Nâng cao nhận thức xã hội}

Những đổi mới quan điểm trên về chế độ sở hữu cần phải được xã hội am hiểu và thực thi khi đã được luật hóa. Do vậy, công tác tuyên truyền, giáo dục, phổ biến những kiến thức về các vấn đề liên quan đển những đổi mới chế độ sở hữu trở nên quan trọng và cần thiết.

Phổ biến những đổi mới trên các phương tiện truyền thông: phát thanh, truyền hình, báo chí. Chú trọng đối tượng các cán bộ lãnh đạo các cấp của Đảng, Chính phủ, Quốc hội cần được quán triệt sâu sắc, để họ có thể thể chế hóa và thực thi. Đưa vào giảng dạy các cấp học trong nhà trường một cách phù hợp.

\section{Đề xuất thí điểm}

Trước khi thực thi rộng rãi các quan điểm mới về chế độ sở hữu. Cần thực hiện thí điểm với các mô hình sau đây:

Một là, xây dựng các khu kinh tế với các thể chế hiện đại, quốc tế, tại đó sẽ thực hiện thí điểm các cơ chế mới về chế độ sở hữu. Chẳng hạn có thể cho phép người nước ngoài thuê đất xây dựng các khách sạn cao cấp với thời hạn 120 đến 150 năm.

Hai là, chọn một số doanh nghiệp nhà nước hiện kinh doanh có lãi nhất, bán toàn bộ cổ phiếu trên thị trường chứng khoán, rút vốn Nhà nước ra và kiểm định xem phần thu thuế sau khi cổ phần hóa có lớn hơn phần thu lợi nhuận trước đó, sau đó 
nhân rộng mô hình này trong tất cả các doanh nghiệp nhà nước mà Nhà nước không cần nắm giữ.

Ba là, chọn 1 tổng công ty hay tập đoàn kinh tế nhà nước đang có nhiều chuyện bê bối làm đối tượng để tái cơ cấu. Lập các nhóm chuyên gia kinh tế có kinh nghiệm nghiên cứu và xử lý các vấn đề bê bối đó và đề xuất các giải pháp.

Bốn là, xây dựng một đề án đổi mới toàn bộ khu vực doanh nghiệp nhà nước theo hướng giảm tỷ trọng và cổ phần hóa giữ lại rất ít doanh nghiệp nhà nước $100 \%$ vốn Nhà nước, còn các doanh nghiệp khổng cần thiết nắm giữ có thể bán, khoán, cho thuê, cổ phần hóa. Đề án này sẽ thực hiện thí điểm một số tỉnh thành phố có lựa chọn.

Năm là, cần có một chiến lược dài hạn phát triển doanh nghiệp tư nhân Việt Nam đủ sức cạnh tranh trên thị trường trong nước và quốc tế.

Võ Đại Lược

\section{TSKH, nguyên Viện trưởng Viện Kinh tế và Chính trị thế giới}

\section{Chú thích:}

1. C.Mác, Ph.Ănghen, V.I.Lênin và chính trị kinh tế học. Nxb. Sự Thật, H.1962, t.21.

2. Võ Đại Lược, Kinh tế Việt Nam - Lý luận và thực tiễn, Nxb. Khoa học xã hội, H. 2011, tr.47.

3. Hội đồng lý luận Trung ương, Những vấn đề lý luận và thực tiễn đặt ra trong tình hình hiện nay, t.II, Nxb. Chính trị quốc gia, H.2010, tr.599.

4. Phạm Minh Chính, Vương Quân Hoàng, Kinh tế Việt Nam - Thăng trầm và đột phá, Nxb. Chính trị quốc gia, H. 2009, tr.154.

Võ Đại Lược. (2021). Tiếp tục đổi mới, hoàn thiện chế độ sở hữu trong nền kinh tế thị trường định hướng XHCN ở Việt Nam. Tạp chí Mặt Trận (Aug 24, 2021). http://

tapchimattran.vn/kinh-te/tiep-tuc-doi-moi-hoan-thien-che-do-so-huu-trong-nen-kinh-te- 


\section{Tài liệu tham khảo:}

1. Nxb Sự Thật (1962), C. Mác, Ph.Ănghen, V.I. Lênin và chính trị kinh tế học. Nxb. Sự Thật, Hà Nội. 1962, t.21.

2. Võ Đại Lược (2011), Kinh tế Việt Nam - Lý luận và thực tiễn. Nxb. Khoa học xã hội, Hà Nội. 2011, tr.47.

3. Hội đồng lý luận Trung ương (2010), Những vấn đề lý luận và thực tiễn đặt ra trong tình hình hiện nay, t.II. Nxb. Chính trị quốc gia, Hà Nội. 2010, tr.599.

4. Phạm Minh Chính, Vương Quân Hoàng (2009), Kinh tế Việt Nam: Thăng trầm và đột phá. Nxb Chính trị quốc gia, Hà Nội. 2009, tr.154. 